yellowish, viscous fluid in which the clusters were suspended. These incidents are mentioned here as suggestive of the similarity in the apparent disturbing results produced by certain factors, "both in the pituitary body and in the corpus luteum.

The usual procedure for collecting the raw material was followed. The ovary containing the corpus luteum was removed from the animal shortly after slaughtering and while still containing the animal heat. The corpora lutea were then carefully dissected out and trimmed free from all adherent tissue, weighed and stored at freezing temperature until the entire lot had been collected. The glands were finely minced, dried on agate-ware trays at a temperature not exceeding $65 \mathrm{C}$. (149 F.) to constant weight and extracted in the Soxhlet apparatus with petroleum benzin. The loss of moisture and petroleumbenzin-soluble material were noted, and the desiccated fat-free substance powdered in a tube-mill to pass a 60-mesh sieve.

The total number of glands, the maximum, minimum and average weights, together with the moisture and petroleum-benzin-soluble material on the fresh glands and yield of desiccated material are given in the accompanying tabulation. On the desiccated fat-free glands the moisture, ash, total nitrogen and total phosphoric acid were determined and the figures calculated to dry basis for comparative purposes.

COMPARISON OF THE CORPORA LUTEA OF PREGNANCY AND OF OVULATION

\begin{tabular}{|c|c|c|}
\hline & -Cornors & \\
\hline & Pregnant & Non-Pregnant \\
\hline 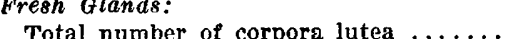 & 692 & $\begin{array}{r}\text { Cows } \\
316\end{array}$ \\
\hline Average weight of corpora lutea, gm... & 4.8 & 4.1 \\
\hline Maximum weight of corpora lutea, $\mathrm{gm}$.. & 18.2 & 10.0 \\
\hline Minimum weight of corpora lutea, gm. & 0.9 & 0.8 \\
\hline Mojsture in fresh glands, per cent..... & 77.0 & 78.9 \\
\hline Petroleum-benzin-soluble, per cent..... & 4.5 & 4.5 \\
\hline Desiccated Fat-Free Glands: & & \\
\hline Yield of desiccated fat-free glands, per & & \\
\hline cent. $\ldots \ldots \ldots \ldots \ldots \ldots \ldots \ldots \ldots$ & 18.5 & 16.6 \\
\hline Moisture, per cent. . . . . . & 4.9 & 5.6 \\
\hline Asb, per cent. $\ldots \ldots \ldots \ldots \ldots \ldots \ldots$ & $\mathbf{5 . 3 3}$ & 6.0 \\
\hline Total nitrogen, per cent. $\ldots \ldots \ldots \ldots \ldots$ & 13.1 & 13.2 \\
\hline Protein $(N \times 6.25)$, per cent. $\ldots \ldots \ldots$ & 81.88 & 82.5 \\
\hline Phosphoric acid $\left(\mathbf{P}_{2} \hat{O}_{5}\right)$, per cent. $\ldots$. & 2.6 & 2.84 \\
\hline Ash, dry basis, per cent. $\ldots \ldots \ldots \ldots$ & 5.6 & 6.36 \\
\hline Nitrogen, dry basis, per cent. $\ldots \ldots \ldots$ & 13.77 & 13.88 \\
\hline Protein, dry basis, per cent. ....... & 86.06 & 86.75 \\
\hline Phosphoric acid, dry basis, per cent.. & 2.73 & 3.01 \\
\hline
\end{tabular}

The tabulated results show that the corpus luteum of pregnancy is larger and shows a greater variation in size than the corpus luteum of ovulation.

When the figures on the dry basis are compared it will be noted that the nitrogen, and consequently the protein as well as the ash and total phosphoric acid contents, are slightly higher in glands from non-pregnant animals than in the true corpora lutea of pregnancy. It is, however, very doubtful if these slight differences are of any significance in judging or determining the therapeutic value of the two varieties of the corpus luteum. The active principle undoubtedly is present in the glands in organic combination and closely associated with the protein complex. Much more extensive work will be required, therefore, before this problem can be solved. It is the intention to continue investigation along these lines.

It may be mentioned here that tests for epinephrin were negative in both varieties, and that the glands did not give more than a very faint indication of the presence of iodin, as would naturally be present in ordinary animal tissues.

\section{THE FREQUENCY OF PREGNANCY IN SLAUGHTER-HOUSE CATTLE IN RELATION TO THE SUPPLY OF CORPUS LUTEUM}

\author{
CAREY PRATT MCCORD, M.D. \\ DETROIT
}

With the advent of corpus luteum to therapeutic importance, we are confronted with the question as to the superiority of extracts from corpus luteum from pregnant animals (corpus luteum verum) over extracts from non-pregnant animals (corpus luteum spurium). In his recent paper, Dannreuther ${ }^{1}$ asserts that only corpora lutea vera bear the substances that are efficacious in gynecologic conditions, and he would explain some of the failures attending the use of this material on the grounds of the material not being obtained from pregnant animals.

There is no anatomic basis for the alleged difference in the two types; the structure is identical. As a rule, the corpus luteum of pregnancy attains a much larger size than the spurious type, but this does not serve to distinguish, for the corpus luteum in the non-pregnant has frequently been found to occupy four fifths of the entire ovary, and in pregnancy the corpus luteum is at times smaller than the average size for non-pregnancy. It has also been suggested that variations in color of corpora lutea stand in some fixed relation to pregnancy and non-pregnancy. The variations in color are merely differences in amounts of blood and lutein cells. Such variations in color usually stand in relation to the age of the corpus luteum. Just after ovulation the blood predominates and gives the dark red color to the corpus luteum; later the blood is absorbed and the yellow color is prominent from the predominance of the lutein cells. Whatever differences there may be, giving rise to greater efficacy from treatment with corpus luteum verum, they probably involve the chemical constituents rather than the structure of the two types of corpus luteum.

In connection with this confronting situation it seemed advisable to determine the frequency of pregnancy in cattle in the packing-houses, inasmuch as this is the source of supply of corpus luteum for pharmaceutical houses. The cattle slaughtered in the larger abattoirs are usually range cattle, the males and females being together at all times. The greater number of the cows of such herds are at some stage of pregnancy. An examination of the ovaries and uteri was made on forty cows appearing consecutively on the killing floors, but of two lots from different parts of the country. The cows so examined were all within the calf-bearing period, but of various ages. Of the forty cows, thirtyfive yielded ovaries containing corpora lutea of such size as permitted dissecting out. Of these thirty-five, twentynine, or 83 per cent. ( 72 per cent. of the entire number), were pregnant. The corpora lutea from these pregnant cows were not uniformly large; many were identical in size and general appearance with those from the non-pregnant animals. Others were so large as to occupy five-sixths of the entire ovary.

From this examination it may be inferred that numerically 83 per cent. of corpus luteum is derived from pregnant cows. On account of the larger yiald of corpus luteum from a pound unit of ovaries from pregnant animals than from the same unit of ovaries from non-

1. Dannreuther, Walter T.: Corpus Luteum Organotherapy in Clinical Practice, ThE Joundal A. M. A., Jan. 31, 1914, p. 359 . 
pregnant animals, because of the larger average size of the former, the proportion by weight may run as high as 90 to 95 per cent. of corpus luteum verum.

These figures may vary on an examination of a larger number of cattle, and furthermore, a seasonal variation may alter the percentage of pregnancy. If the foregoing figures at all approximate the general condition, all corpus luteum preparations are derived in a high percentage from pregnant cattle.

960 Waterloo Avenue.

\section{A SIMPLIFICATION OF THE GRAM STAIN}

LOUIS D. SMITH, B.S., M.D.

Assistant in the Department of Genito-Urinary Diseases, Rush Medical College

CHICAGO

Having been impressed with the importance of the Gram stain as a routine Jaboratory procedure in bacteriologic examinations, and with the fact that, as ordinarily performed, it is time-consuming (involving from five to ten minutes), and comparatively laborious, I evolved the following simple technic, with the idea of eliminating the time element as far as possible without impairing its reliability:

Six wide-mouthed, 4-ounce bottles are numbered from 1 to 6 and labeled according to the following ingredients: Bottle 1 contains alcohol-saturated gentian-violet with distilled water in the proportion of 1 part stain to 3 parts water. Bottle 2 contains plain distilled water, Bottle 3 Gram's solution, Bottle 4 absolute methyl alcohol, Bottle 5 piain distilled water and Bottle 6 dilute Ziehl-Neelsen carbolfuchsin (about $1: 10$ ), whose speedy and penetrating staining properties are well known. The elements of the stain differ from the original technic in two essential details, namely, the employment of plain water for the gentian solution in place of anilin-water (this may be used nevertheless), and most important, the substitution of absolute methyl alcohol for ethyl alcohol, as the destaining agent. The reason for this substitution is that the former acts far more quickly and efficaciously, thereby featuring a desirable timesaring phase.

In performing the Gram stain, the slide is dipped into Bottle 1 for from five to ten seconds with constant stirring, is transferred to Bottle 2 for a few seconds, excess water being shaken off, then to Bottle 3 for five seconds with constant agitation of slide, thence to Bottle 4, where it takes but a few seconds to destain, especially if stirred, then transferred to Bottle 5 to wash (if it is not yet destained, the slide is returned to Bottle 4 again), and lastly to Bottle 6 for a couple of seconds. It is washed off in tap-water. The staining and counterstaining, it will be seen, have been performed in about one minute.

It will be noticed that after staining with gentianviolet the slide is washed in water. According to good authorities, washing the slide with water, before destaining, is permissible in the employment of the Gram stain. My reason for using Bottle 2 is that by washing off excess stain the precipitation of the Gram solution is minimized. Finally, the only frequent change necessary is that of the wash-water, since the gentian stain itself, I have found, does not deteriorate rapidly.

32 North State Street.

\section{Therapeutics}

\author{
THE' TUBERCULOSIS PROBLEM \\ (Continued from page 1169)
}

TREATMEN'T OF SYMPTOMS

Fever.-Nothing tends to diminish the temperature more than the rest, quiet and fresh-air treatment already outlined. The patient who has high fever should not be given too much food at any time of day, even if the disease is tuberculosis; and most of what he does receive should be given during an afebrile period if possible. If he is suffering from acute tuberculosis, the nutrition should be much the same as for any other serious fever.

Sponging with hot water will often give these patients comfort, and, if they have profuse sweats, it keeps the skin clean. The frequency of such sponging will, of course, depend on the height of temperature and its continuance. Antipyretics are rarely indicated.

Cough.-The treatment of the cough depends on whether it is dry or moist, and whether expectoration is easy or difficult. If the cough is dry and hacking, much of it may be prevented by the will-power of the patient. It should not be forgotten that many dry, irritating coughs are due to a lingual tonsil or throat irritation. Soothing, alkaline gargles, non-irritating inhalations of simple steam or steam medicated with some nonirritant drug, as a small amount of a pine oil, will give relief. Many coughs of this kind are relieved by swabbing the lingual tonsil with boroglycerid. These dry, irritating coughs should be relieved without giving medicine by the stomach.

If there is considerable bronchitis with insufficient expectoration, or the cough is frequent without expectoration, no cough mixture is any more soothing or behaves better in the stomach than the following:

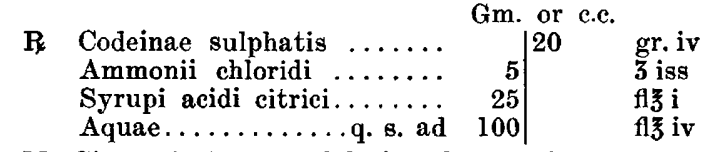

M. Sig.: A teaspoonful, in plenty of water, every two, three or four hours, as needed.

Heroin may be used in place of codein if desired, but we believe that codein is the best sedative preparation of the opium series to meet the indication. The action of all other expectorants is inferior to that of ammonium chlorid, and ammonium chlorid as prescribed above is not very disagreeable. The dose may be taken in Vichy or other sparkling water if desired. None of the multiple sweet, sickish, syrupy preparations offered by proprietary firms should be used in the bronchitis and catarrh of tuberculosis, or in any other kind of bronchitis. It is not necessary to cause nausea or vomiting because a patient has a cough. The success of some of these syrups or malt preparations in dry cough is due to the fact that they soothe the throat and lingual tonsil. Such irritation can be allayed without the patient swallowing a mixture. If the cough is loose, and if expectoration is profuse, the stimulating effect of ammonium chlorid and the sedative effect of codein are not needed, and terpin hydrate becomes the best drug to use, as an expectorant. To meet this indication of profuse bronchorrhea it will not ordinarily be necessary to combine it with either codein or heroin. It should never be given in solutions, as not enough of it to be of advantage will be dissolved in any solution. It may be given in tablet, powder or capsule, and the 